\title{
Mosquito Surveillance for West Nile Virus in Southeastern Wisconsin - 2002
}

\author{
Jennifer K. Meece, PhD, Center for Tropical Disease Research and Training, University of Notre Dame, Notre Dame, Indiana, \\ and Clinical Research Center, Marshfield Medical Research Foundation, Marshfield, Wisconsin \\ James S. Henkel, BS, University of Wisconsin-LaCrosse, LaCrosse, Wisconsin \\ Linda Glaser, DVM, Wisconsin Department of Health and Family Services, Madison, Wisconsin \\ Kurt D. Reed, MD, Clinical Research Center, Marshfield Medical Research Foundation, Marshfield, Wisconsin
}

[See related article: 5-12]

\begin{abstract}
In 2001, West Nile virus (WNV) was identified among dead American crows and bluejays in five counties in southeastern Wisconsin. In response to the introduction of WNV, a pilot mosquito surveillance program was initiated in these five southeastern Wisconsin counties during the summer of 2002. Forty sites were selected for surveillance one night each week during a 17-week period. Mosquitoes were collected in carbon dioxide-baited light traps and gravid traps. During the study period 31,419 mosquitoes were collected, identified to species level and pooled into groups of up to 50 mosquitoes of like species from each collection site. Twenty-five different mosquito species were identified with the common pest mosquitoes, Aedes vexans and Ochlerotatus trivittatus, being the most abundant. Seventeen of the 25 mosquito species found in southeastern Wisconsin have previously been shown to be carriers of WNV in other parts of the U.S. Only 2/1,592 (0.126\%) mosquito pools from Wisconsin were positive for WNV by cell culture and reverse transcription polymerase chain reaction (RT-PCR). Active mosquito surveillance is useful for identifying potential mosquito vectors of arboviruses in defined geographic areas, and to monitor population densities of those vectors. This information coupled with infection rate data can help guide public health policies related to vector control, and may help reduce the impact on human, veterinary and bird mortality.
\end{abstract}

REPRINT REQUESTS:

Jennifer Meece, PhD

Clinical Research Center

Marshfield Medical Research Foundation

1000 North Oak Avenue

Marshfield, WI 54449

Telephone: 715-389-5142

Fax: $715-389-3808$

Email: meece.jennifer@marshfieldclinic.org
KEYWORDS:

Mosquito, West Nile virus, Surveillance 


\section{INTRODUCTION}

West Nile virus (WNV) is a mosquito-borne virus that was first isolated from the blood of a sick woman in the West Nile District of Uganda in 1937. ${ }^{1}$ The virus is widely distributed in the Old World, but appeared for the first time in the Western Hemisphere in the summer of 1999. In the initial outbreak in the New York City area, 62 clinical cases were confirmed, including 7 mortalities. ${ }^{2}$ Subsequent immunoserological testing in the epicenter indicated that $2-6 \%$ of the population, or up to 13,000 people, may have been exposed to the virus. ${ }^{3}$ In addition to human infections, significant morbidity and mortality occurred among wild birds, the main amplifying host for the virus in nature and in horses. 4,5

In 2000 and 2001 the virus expanded westward in the continental United States. By the end of 2001, the virus was identified as far west as the Mississippi River. As of October 8, 2002, the virus was identified in all states in the continental U.S. except Arizona, Utah, Nevada, Idaho and Oregon. ${ }^{6}$ Also, 2,768 laboratory confirmed human cases of WNV and 146 human mortalities have been reported as of October 8, 2002 by the Centers for Disease Control and Prevention (CDC). ${ }^{7}$

WNV is maintained in nature by cycles of transmission between birds and mosquitoes. A mosquito becomes infected after taking a blood meal from a vertebrate host that has a high level of circulating virus. It requires approximately $10-$ 14 days for a mosquito to become infectious to another animal after receiving its initial infected blood meal. This time interval is known as the intrinsic incubation period. When a mosquito takes a blood meal containing the virus, the virus moves into the mosquito gut where it invades the midgut cells and moves across the midgut to invade other mosquito tissues. Eventually the salivary glands of the mosquito are invaded. When a mosquito takes a blood meal, the mosquito injects a small amount of saliva and virus into the host. The amount of time for a bird to attain a viremia sufficient to infect another uninfected mosquito varies from species to species. However, species such as crows become infectious within 3-5 days and experience high mortality from the infection. In order for a mosquito to actively transmit WNV from host to host, it must survive the intrinsic incubation period to take another blood meal. ${ }^{8}$

Historical data suggest that more than 50 species of mosquitoes may be present in Wisconsin. ${ }^{9}$ Breeding habitats, life histories and feeding habits vary significantly from species to species. Therefore, characterizing the types of mosquitoes present in endemic areas can be important in determining and implementing appropriate public health policies. For example, Culex spp. mosquitoes are known to be primarily ornithophilic (bird loving) in their feeding preferences. Because WNV is primarily transmitted between mosquitoes and birds, the majority of mosquito isolates have been from
Culex spp. mosquitoes. ${ }^{10-13}$ The risk to humans and to other mammals from Culex spp. is less than the risk for birds. However, other mosquitoes, such as Aedes vexans are known to be opportunistic feeders. These mosquitoes will take a blood meal from a wide variety of hosts. These "bridge vectors" pose a more serious risk to human and other mammals. ${ }^{12}$ The third category of feeding preferences is known as mammalophilic (mammal loving). Examples of this type of mosquito are Ochlerotatus canadensis, Ochlerotatus triseriatus, and Ochlerotatus trivittatus. ${ }^{12}$

The CDC has published guidelines for monitoring WNV and other arboviruses in the U.S. The goal of these comprehensive surveillance programs is to identify WNV activity in birds, mosquitoes and horses as sentinels for potential outbreaks in humans. Important goals of mosquito surveillance are to identify potential mosquito vectors in a particular area, monitoring population densities of those vectors and determining infection rates. ${ }^{14}$

In 2001, the first WNV-positive birds were identified in five southeastern Wisconsin counties (Dane, Waukesha, Kenosha, Racine and Milwaukee). As a result of WNV introduction into the state, a response plan was organized for the anticipated further spread of WNV across Wisconsin. Prior to 2002, mosquito surveillance in Wisconsin was limited to a few counties or communities that chose to perform surveillance themselves, or to contract with private companies for surveillance and control. In June 2002 a pilot surveillance program in Wisconsin was initiated by a statewide task force under the direction of the Department of Health and Family Services to characterize mosquito species present in the WNV endemic area. The goals of the study included identifying and assessing relative abundance of the various mosquito species, and to test pooled samples for the presence of WNV. This article summarizes the results of mosquito surveillance and virus testing for the period June 1 to October 1, 2002.

\section{METHODS}

Forty trap sites were identified in five counties in southeastern Wisconsin. Trap sites were selected based on proximity to WNV-positive dead birds collected in the previous year, and areas where humans were considered to have increased exposure to mosquitoes, such as in public parks and golf courses. Based upon anticipated mosquito activity, six sites each in Kenosha and Racine counties and eighteen sites in Milwaukee County were monitored beginning the first week of June and continued through October 1, 2002. Six sites in Dane county were monitored beginning the first week of June and continued through the middle of August. Four trap sites in Waukesha County were monitored beginning the first week of July and continued through October 1, 2002. The number of traps and duration of surveillance varied by county based upon health department availability and willingness to assist in trapping. 
An ABC carbon dioxide-baited light trap (Clarke Mosquito Control, Chicago, IL) was set out one night a week, at each site. The traps work by attracting female mosquitoes questing for a blood meal. Questing female mosquitoes are attracted to the carbon dioxide and heat emitted by the trap. Mosquitoes attracted to the traps are drawn into a collection bag by a small battery operated fan.

Six gravid traps (John W. Hock Company, Gainesville, FL) were also used on a rotating basis at sites in Racine, Kenosha, Milwaukee and Dane counties. Waukesha County elected not to use this type of trap. The traps work by attracting gravid females who are seeking oviposition sites. The traps are baited with a foul-smelling, organically enriched liquid. Many mosquitoes, particularly Culex spp., seek stagnant water for laying eggs. Although the number of mosquitoes collected in a gravid trap tends to be much smaller than in a light trap, the likelihood of obtaining a virus-positive mosquito is higher. Gravid females seeking an oviposition site have already taken a potentially infectious blood meal.

Each trap was set between 2:00 p.m. and 5:00 p.m., and collected the following morning. The mosquitoes were transported back to the laboratory where they were freeze-killed and stored at $-80^{\circ} \mathrm{C}$. The mosquitoes were packaged in $50 \mathrm{~mL}$ vials and transported on dry ice to the Marshfield Medical Research Foundation for identification and testing.

In addition to the routine trap sites, collections of mosquitoes were obtained from two sites (Milwaukee County and Adams County) that were known to have WNV activity based on the presence of WNV-positive dead birds or from human cases. At these sites two additional collection methods were utilized in an effort to conduct intensive on-site collections. These methods included a large hand-held aspirator that collects mosquitoes resting in brush, grass and vegetation, and a smaller hand-held aspirator used to collect mosquitoes in confined spaces such as storm sewers, viaducts and buildings.

Each mosquito was identified to species level using standard morphologic criteria. ${ }^{9,15}$ Like species from each site were pooled in groups that may consist of a minimum of 1 to a maximum of 50 mosquitoes. In some instances mosquitoes were fragmented and abraded, and could not be accurately identified. When this occurred, mosquitoes from these sites were pooled and classified as unidentified. Chill tables were used to maintain a cold chain throughout identification and processing.

Pools were homogenized in a cell culture media (DMEM supplemented with $10 \%$ fetal bovine serum and antibiotic/antifungicide) in1-dram vials containing glass beads and tested for virus by plaque assay. Plaque assays were performed using Vero cells (American Type Cell Culture, Manassas, VA) in 6-well plates. Plates were inoculated with the mosquito homogenate and virus allowed to adsorb to the monolayer for one hour. The homogenate was then removed and a media/gum tragacanth overlay was applied. Culture plates were incubated at $37^{\circ} \mathrm{C}$ for 5 days. The media was then aspirated off the monolayer, the plate stained with a formaldehyde/crystal violet stain and examined for the presence of plaques. Positive plaque assays were confirmed by reverse transcription polymerase chain reaction (RT-PCR).

For RT-PCR, RNA was extracted using a Qiagen RNeasy mini kit (Qiagen, Valencia, CA). A $15 \mu \mathrm{L}$ RT-PCR reaction using the Roche Light Cycler RT-PCR kit (Roche Molecular

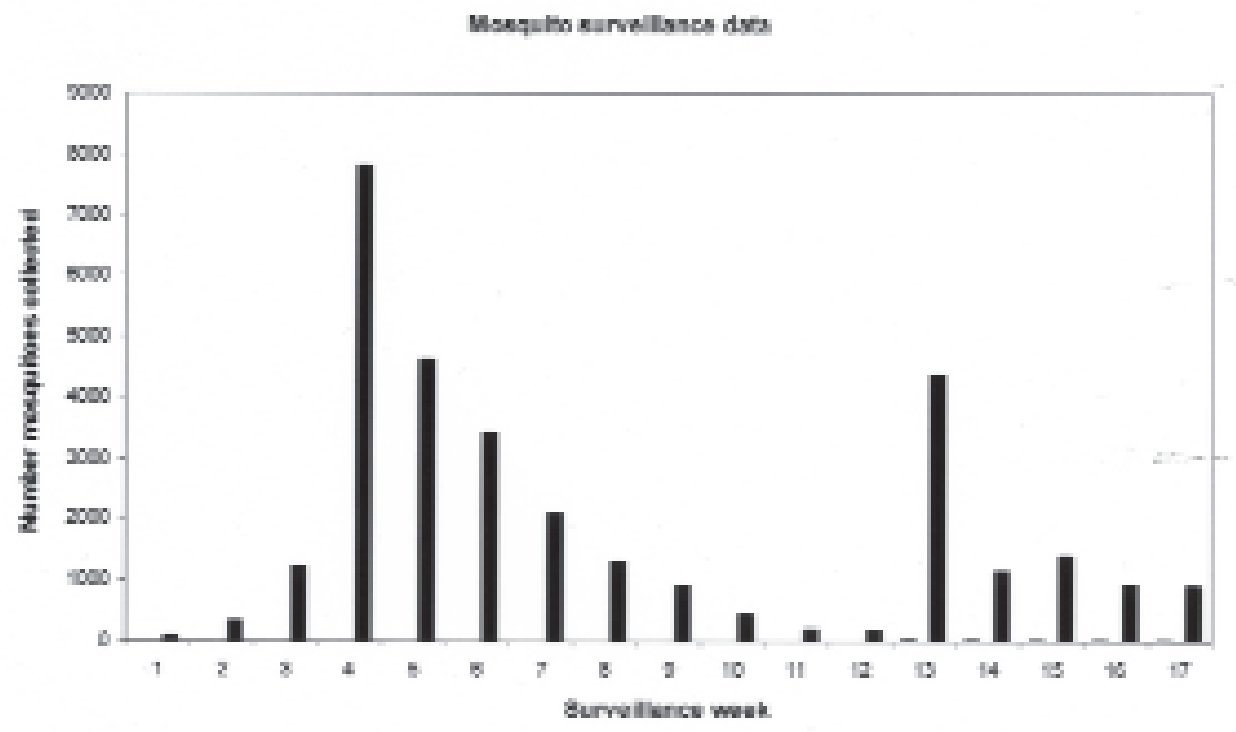

Figure 1. Number of mosquitoes collected each week. Each week the number of trap sites that yielded mosquitoes varied. 
Table 1.

Most abundant mosquito species collected during 2002 surveillance in five Wisconsin counties.

\begin{tabular}{|c|c|}
\hline $\begin{array}{l}\text { Mosquito } \\
\text { species }\end{array}$ & $\begin{array}{l}\text { Number } \\
\text { collected }\end{array}$ \\
\hline Aedes vexans ${ }^{1}$ & 13,364 \\
\hline Ochlerotatus trivittatus ${ }^{1}$ & 9,248 \\
\hline Culex tarsalis ${ }^{1}$ & 1096 \\
\hline Coquillettidia perturbans ${ }^{1}$ & 765 \\
\hline Culex pipiens/restuans ${ }^{1,2}$ & 679 \\
\hline Ochlerotatus canadensis ${ }^{1}$ & 233 \\
\hline Culex erraticus ${ }^{1}$ & 191 \\
\hline Ochlerotatus triseriatus 1 & 167 \\
\hline All other species ${ }^{3}$ & 314 \\
\hline $\begin{array}{l}\text { Aedes cinereus }{ }^{1} \\
\text { Anopheles }^{\text {Anucians }}{ }^{1} \\
\text { Anopheles punctipennis }^{1} \\
\text { Anopheles quadrimaculatus } \text { s.l. }^{1} \\
\text { Anopheles walkeri } \\
\text { Culex salinarius }^{1} \\
\text { Culiseta inornata }^{1} \\
\text { Culiseta morsitans } \\
\text { Ochlerotatus abserratus } \\
\text { Ochlerotatus dorsalis } \\
\text { Ochlerotatus excrucians } \\
\text { Ochlerotatus fitchii } \\
\text { Ochlerotatus sollicitans }{ }^{1} \\
\text { Ochlerotatus stimulans } \\
\text { Psorophora ferox }{ }^{1} \\
\text { Uranotaenia sapphirina }{ }^{1}\end{array}$ & \\
\hline Unidentified species & 5,362 \\
\hline Total & 31,419 \\
\hline
\end{tabular}

1 Indicates mosquito species from which WNV has been isolated in the United States. Virus isolation from field-collected specimens does not incriminate a mosquito as a competent vector. This determination requires more extensive transmission study.

2 Because of only minor morphological differences between these species, they are often difficult to discriminate and therefore are often pooled together.

3 Sixteen additional species were identified with the total number under 50 individuals/species.
Biochemicals, Indianapolis, IN) was performed under the following conditions: $0.125 \mu \mathrm{M}$ forward primer (WNV F34 5'CCACCGGAAGTTGAGTAGACG 3'); $0.5 \mu \mathrm{M}$ reverse primer (WNV R96 5'TTTGGTCACCCAGTCCTCCT 3'); $0.09 \mu \mathrm{M}$ FAM/TAMRA labeled probe (WNV 56 5'TGCTGCCTGCGGCTCAACCC 3'); $5 \mathrm{mM} \mathrm{MgCl}{ }_{2}$; $4.0 \mu$ L RT-PCR reagent vial 2; $0.5 \mathrm{U}$ uracil nucleotide glycosylase; and 0.4 $\mu \mathrm{L}$ RT enzyme. PCR cycling parameters were as follows: 1 cycle at $50^{\circ} \mathrm{C}$ for 60 seconds; 1 cycle at $55^{\circ} \mathrm{C}$ for $1,500 \mathrm{sec}-$ onds; 1 cycle at $95^{\circ} \mathrm{C}$ for 240 seconds; 40 cycles of $95^{\circ} \mathrm{C}$ for 0 seconds followed by $60^{\circ} \mathrm{C}$ for 20 seconds; and 1 cycle at $40^{\circ} \mathrm{C}$ for 30 seconds. ${ }^{16}$ Positive and negative controls were included in each run. Positive controls were RNA obtained from the Wisconsin State Laboratory of Hygiene. Negative controls consisted of master mix minus RNA template.

\section{RESULTS}

Mosquito abundance for each week of the collection period is shown in figure 1. In total 31,419 mosquitoes were collected between the first week of June and October 1, 2002. These were divided into 1,592 pools. The first four weeks of surveillance do not contain data from Waukesha County. Dane County discontinued the surveillance effort following week 12. As a result, weeks 13 - 17 do not contain data from Dane County.

Twenty-five mosquito species were identified (table 1). The six most abundant mosquito species collected were Aedes vexans, Ochlerotatus trivittatus, Culex tarsalis, Coquillettidia perturbans, Culex pipiens/restuans, and Ochlerotatus canadensis. During the 5 weeks with the highest counts (weeks 4, 5, 6, 7 and 13) two species, Aedes vexans and Ochlerotatus trivittatus, together accounted for $92.5 \%$, $81.4 \%, 78.2 \%, 60.5 \%$ and $89.9 \%$, of the total weekly count, respectively. The six most abundant species are known to be highly competent vectors of WNV and other arboviruses. In addition, 17 of the 25 total mosquito species found in southeastern Wisconsin have been shown to carry WNV in other parts of the U.S.

Two of 1,592 (0.126\%) mosquito pools were culture-positive for WNV. These results were confirmed by RT-PCR. The first positive pool was obtained from a light trap in week 13 of surveillance and originated from Milwaukee County. The species of mosquitoes in the positive pool were classified as unidentified because of the poor condition in which they arrived for sorting. Only three other species were collected at this site during this week. These included Culex

pipiens/restuans, Aedes vexans, and Ochlerotatus trivittatus. Six additional species were collected at this site over the course of the trapping season, however, in very low abundance $(<10$ individuals/species). The second positive pool was obtained from a light trap in week 15 of surveillance from a single Culex pipiens/restuans mosquito. 


\section{DISCUSSION}

Active mosquito surveillance performed from June through October 2002 in five southeastern Wisconsin counties provided new information on the number of mosquito species present and their relative abundance. Over 31,000 mosquitoes were collected and included 25 different species. This is in comparison to the approximately 50 species known to exist in Wisconsin. ${ }^{9}$ The majority of the species (17 of 25) collected from the study area are known to carry WNV in the U.S., but not all of them are known with certainty to be competent vectors. Only two of 1,592 (0.125\%) mosquito pools were positive for WNV. One possible explanation for such a low percentage of positives is that collection began in the beginning of June, two months before WNV activity peaked, based on dead bird surveillance and diagnosis of human cases. In addition, Culex spp., the most common vectors of WNV in other areas of the U.S., represented a relatively small percentage of the total number of mosquito pools tested.

The most common intervention taken for the prevention of arboviral infections is vector control, i.e., larviciding mosquito breeding sites or spraying for adult mosquitoes in densely populated areas. Determining whether or not to initiate vector control is a complicated process because numerous ecological and other variables affect mosquito populations. Also the risks of pesticide use balanced against the risk to humans must also be considered. ${ }^{17}$ In Wisconsin there is limited baseline data on the distribution of most mosquito species and their population densities. A single year of surveillance data is generally insufficient to make such determinations.

As more is learned about the role of various mosquito species in the transmission of diseases such as WNV, it becomes apparent that disease transmission cycles are complex and multifactoral. Future research will include continued surveillance of mosquitoes, tracking virus movement with the aid of viral sequence data, and identifying bird species involved in the spread of such diseases. All parts of the world face the ongoing threat of continued introduction of diseases previously unknown to their area. Mosquitoes, ticks and other disease vectors transmit many of these emerging and infectious diseases. An understanding of the ecology and distribution of these vectors will continue to play an important role in understanding the spread of human and veterinary diseases.

\section{ACKNOWLEDGMENTS}

The authors wish to thank Marshfield Medical Research Foundation for its support through the assistance of Alice Stargardt in the preparation of this manuscript. We also wish to thank the following individuals and organizations for participating and assisting in the surveillance efforts: David Kachelmeyer, Luke Fraundorf, Chris Michelski, David Campbell, City of Milwaukee Department of Public Health, City of Racine Health Department, City of Kenosha Health Department, Dane County Health Department and Waukesha County Health Department.

\section{REFERENCES}

1. Smithburn KC, Hughes TP, Burke AW, Paul JH. A neurotropic virus isolated from the blood of a native of Uganda. Am J Trop Med 1940;20: 471-492.

2. Asnis DS, Conetta R, Teixeira AA, Waldman G, Sampson BA. The West Nile virus outbreak of 1999 in New York: the Flushing Hospital experience. Clin Infect Dis 2000;30: 413-418.

3. Mostashari F, Bunning ML, Kitsutani PT, Singer DA, Nash D, Cooper MJ, Katz N, Liljebjelke KA, Biggerstaff BJ, Fine AD, Layton MC, Mullin SM, Johnson AJ, Martin DA, Hayes EB, Campbell GL. Epidemic West Nile encephalitis, New York, 1999: results of a household-based seroepidemiological survey. Lancet 2001;358: 261-264.

4. Trock SC, Meade BJ, Glaser AL, Ostlund EN, Lanciotti RS, Cropp BC, Kulasekera V, Kramer LD, Komar N. West Nile virus outbreak among horses in New York State, 1999 and 2000. Emerg Infect Dis 2001;7: 745-747.

5. Komar N, Panella NA, Burns JE, Dusza SW, Mascarenhas TM, Talbot TO. Serologic evidence for West Nile virus infection in birds in the New York City vicinity during an outbreak in 1999. Emerg Infect Dis 2001;7: 621-625.

6. Centers for Disease Control and Prevention. Statistics, Surveillance, and Control. Maps and Data. http://www.cdc.gov/ncidod/dvbid/westnile/surv\&control.htm $(10 / 10 / 02)$.

7. Centers for Disease Control and Prevention. West Nile Virus Update Current Case Count. http://www.cdc.gov/od/oc/media/wncount.htm $(10 / 10 / 02)$.

8. Woodring JL, Higgs S, Beaty BJ. Natural cycles of vector-borne pathogens. In: Beaty BJ, Marquardt WC, editors. The Biology of Disease Vectors. Niwot, CO: University Press of Colorado; 1996.

9. Darsie RF Jr, Ward RA. Identification and geographical distribution of the mosquitoes of North America, North of Mexico. Mosquito Suppl 1981;1: 1-313.

10. Nasci RS, White DJ, Stirling H, Oliver JA, Daniels TJ, Falco RC, Campbell S, Crans WJ, Savage HM, Lanciotti RS, Moore CG, Godsey MS, Gottfried KL, Mitchell CJ. West Nile virus isolates from mosquitoes in New York and New Jersey, 1999. Emerg Infect Dis 2001;7: 626-630.

11. Bernard KA, Maffei JG, Jones SA, Kauffman EB, Ebel G, Dupuis AP 2nd, Ngo KA, Nicholas DC, Young DM, Shi PY, Kulasekera VL, Eidson M, White DJ, Stone WB, Kramer LD; NY State West Nile Virus Surveillance Team. West Nile virus infection in birds and mosquitoes, New York State, 2000. Emerg Infect Dis 2001;7: 679-685.

12. Kulasekera VL, Kramer L, Nasci RS, Mostashari F, Cherry B, Trock SC, Glaser C, Miller JR. West Nile virus infection in mosquitoes, birds, horses, and humans, Staten Island, New York, 2000. Emerg Infect Dis 2001;7: 722-725.

13. Apperson CS, Harrison BA, Unnasch TR, Hassan HK, Irby WS, Savage HM, Aspen SE, Watson DW, Rueda LM, Engber BR, Nasci RS. Hostfeeding habits of Culex and other mosquitoes (Diptera: Culicidae) in the Borough of Queens in New York City, with characters and techniques for identification of Culex mosquitoes. J Med Entomol 2002;39: 777-785. 
14. Centers for Disease Control and Prevention. Epidemic/Epizootic West Nile Virus in the United States: Revised Guidelines for Surveillance, Prevention, and Control. April 2001.

http://www.cdc.gov/ncidod/dvbid/westnile/resources/wnv-guidelinesapr-2001.pdf.

15. Siverly RE. Mosquitoes of Indiana. Indianapolis, Indiana State Board of Health, 1972; $126 \mathrm{pp}$.

16. Hadfield TL, Turell M, Dempsey MP, David J, Park EJ. Detection of West Nile virus in mosquitoes by RT-PCR. Mol Cell Probes 2001;15: 147150.

17. Thier A. Balancing the risks: vector control and pesticide use in response to emerging illness. J Urban Health 2001;78: 372-381. 